\title{
The multitemporality of life: an analysis from Philosophy of Biology
}

\author{
Constanza Rendón ${ }^{1}$, Nahuel Pallitto ${ }^{2}$, Guillermo Folguera ${ }^{3}$ \\ ${ }^{1}$ Universidad de Buenos Aires \\ Facultad de Ciencias Exactas y Naturales \\ Intendente Güiraldes, 2160 \\ Buenos Aires 1438 \\ Argentina \\ constanzarendon@yahoo.com \\ ${ }^{2}$ Universidad de Buenos Aires \\ Piran, 6072 \\ Buenos Aires 1431 \\ Argentina \\ nahuelpallitto@hotmail.com \\ ${ }^{3}$ Universidad de Buenos Aires \\ Buenos Aires \\ Argentina \\ guillefolguera@yahoo.com.ar
}

Article info

CDD: 574.1

Received: 09.08.2016; Accepted: 04.10.2016

DOI: http://dx.doi.org/10.1590/0100-6045.2016.V39N3.CNG

Keywords:

Temporality

Biological processes

Evolution

Development

Philosophy of Biology

\section{ABSTRACT}

Although the issue of temporality has mainly been studied from Physics, this topic also exhibits diverse interesting aspects that could be addressed from a biological perspective. One possible way of approaching this subject is to examine the kinds of temporalities involved in biological processes. In that vein, the aim of this article is to analyze developmental and evolutionary processes' temporality in different biological fields of study, including a novel area (Evolutionary Developmental Biology) which attempts to integrate the research of those

Manuscrito - Rev. Int. Fil. Campinas, v. 39, n. 3, pp. 121 - 147, jul.-set. 2016. 
processes. To that end, we propose a taxonomy for the analysis of the temporal characteristics of biological processes. Making use of that taxonomy, we conclude that biological processes' temporality is extremely complex since not only different fields of study present differing temporal characteristics, but also each kind of biological process shows diverse temporalities. These observations point out the pertinence of biological insights and the relevance of Philosophy of Biology's contributions to the study of the extensive and multifaceted issues of time and temporality.

\section{The processes of life and their multiple temporalities}

One of the main issues studied by philosophers of science corresponds to the temporality of natural processes. Historically, philosophical reflections concerning this topic were primarily based on Physics (Savitt 2014, Dowden 2016). Hence, from a scientific perspective, Physics was conceived as a privileged field of study to think about time and how it should be conceptualized. Conversely, the temporality of biological processes has only been marginally analyzed (Reiss 1989, Zaragüeta Bagils et al. 2004, Cracraft 2005, Rasskin-Gutman and Esteve-Altava 2009), with the notable exception of John Haldane's (1967) classic work on this subject. Overall, these studies show that temporality in Biology exhibits diverse interesting aspects which might be addressed from quite different perspectives. Thus, biological phenomena, with their multiplicity of levels of organizations and complexity, constitute excellent epistemic objects to study the multi-faceted theme of temporality.

One possible way to approach the topic of temporality in Biology might be to analyze the kinds of temporalities involved in different biological processes. In this article we will specifically focus on two different types of biological processes: developmental (i.e., changes that organisms experience since conception until death) and evolutionary processes (i.e., historical transgenerational changes of living beings). Moreover, evolutionary processes include microevolutionary (evolution of populations) and macroevolutionary processes (changes concerning higher taxonomic groups). At first glance, it would be expected that all these processes present differing temporal characteristics since they refer to changes that occur at quite different timescales. Besides, these processes have traditionally been studied separately by distinct biological fields: while Evolutionary Biology

Manuscrito - Rev. Int. Fil. Campinas, v. 39, n. 3, pp. 121-147, jul.-set. 2016. 
has focused on micro and macroevolution, Developmental Biology has centered on the development of organisms (Fox Keller 2000, Amundson 2005, Love 2006, Laubichler and Maienschein 2007). However, since the 1990s, a new area of Biology named Developmental Evolutionary Biology (EvoDevo) has been attempting to integrate the study of evolutionary and developmental processes. EvoDevo currently constitutes a flourishing field which comprises diverse research programs (Laubichler and Maienschein 2007, Müller 2008, Pigliucci and Müller 2010). Besides, the integrative challenge undertook by EvoDevo has been the subject of multiple theoretical and philosophical analyses (Amundson 2005, Laubichler and Maienschein 2007, Rendón 2015).

In this context, the main objective of this paper is to analyze the temporality of EvoDevo's processes. Our primary hypothesis is that EvoDevo, as a field that integrates different kinds of biological processes, presents multiple temporalities. In order to test this hypothesis and understand the biological meaning of that expected multitemporality, we will first propose a taxonomy for analyzing the temporality of biological processes (Section 2). Secondly, we will use this taxonomy to identify the temporal characteristics of the processes addressed by Evolutionary Biology and Developmental Biology (Section 3). Once the temporal characteristics of evolutionary and developmental processes have been identified, we will examine the temporality of EvoDevo's processes (Section 4). Finally, in Section 5 we will offer some conclusions about the meaning of EvoDevo's multitemporality and the multiple kinds of temporalities involved in living beings' processes. We will also examine the implications of these results regarding the relevance of biological insights and Philosophy of Biology's contributions on the issues of time and temporality.

\section{A taxonomy for the analysis of biological processes' temporality}

In this paper we shall take the term 'process' to mean a succession of states linked to a certain mechanism. In order to examine the temporality of biological processes, we propose a taxonomy consisting of four temporal categories. We will present and define each of these categories below.

i) Type of trajectory

Manuscrito - Rev. Int. Fil. Campinas, v. 39, n. 3, pp. 121 - 147, jul.-set. 2016. 
This category describes the order and way in which states succeed each other in any particular process. We distinguish between three different types of trajectories:

a) Linear trajectory: in this kind of trajectory different states follow each other in a definite direction. The identification of the specific property which guarantees such directionality depends on the process in question. An example of this kind of process is an organism's growth. In that case, the linear increase of certain morphological variables (for instance, height) confers directionality to the process.

b) Cyclical or recurring trajectory: we will conceive cyclic processes as those in which there is a repetitive alternation between at least two states, as follows:

\section{S1-S2-S1-S2-S1-S2 ....,}

where S1 and S2 represent different states of the process.

Living beings' circadian rhythms (such as the alternation between states of sleep and wakefulness in animals) are examples of cyclical processes.

c) Helical or quasi-recurring trajectory: this kind of trajectory is a consequence of a particular property of certain biological processes known as recursion (Morin 1983). Recursion implies that the process' final state is a necessary and sufficient condition for restarting that same process. However it is hard to find strict recursion in living beings because states of biological processes are not repeated exactly in the same way. Instead, derived states share morphological and/or functional similarities with the previous ones (also being generated as products or effects of the previous states). This type of trajectory might be depicted as a loop or a helix, as follows:

$$
\text { S1-S2-... Sn-S1'-S2'...Sn' }
$$

where state $\mathrm{Sn}$ is a necessary and sufficient condition to generate S1' state. S' states represent similar states to the corresponding $\mathrm{S}$ states.

Manuscrito - Rev. Int. Fil. Campinas, v. 39, n. 3, pp. 121-147, jul.-set. 2016. 
An organism's life cycle regeneration is an example of a process that presents a helical type of trajectory. In this case, certain parental life cycle's states are necessary and sufficient conditions for restarting the cycle in a new generation, which in turn will develop similar (but not identical) states to the ones of the parental life cycle.

\section{ii) Reversibility}

We will say that a process is reversible if it admits the regression to previous states. A case of reversibility might take the following form:

$$
\text { S1-S2-S3-S2-S3-S4 ... Sn }
$$

iii) Rate of change

We will use this category to refer to the variation of speed in the transitions between different states. We shall distinguish between processes that present a uniform (constant) rate of change and those which show a variable rate of change.

\section{iv) Duration}

This category refers to the time interval extension comprised between the process' initial and final states.

In the next sections we will use this taxonomy to characterize the temporality of evolutionary and developmental processes.

\section{Analysis of evolutionary and developmental processes' temporality}

In this section we will examine the temporality of microevolutionary (Section 3.1), macroevolutionary (Section 3.2) and developmental processes (Section 3.3). We will close Section 3 with a summary of the obtained results for each of the analyzed processes (Section 3.4).

Manuscrito - Rev. Int. Fil. Campinas, v. 39, n. 3, pp. 121 - 147, jul.-set. 2016. 


\subsection{Microevolutionary processes: reversibility and uniformity in the evolution of populations}

From the 1930s, evolution started to be principally accounted for by an hegemonic theoretical framework termed 'Synthetic Theory of Evolution' or 'Modern Synthesis' (MS). The MS's main concern was the explanation of microevolutionary processes. At the core of the MS lied Population Genetics, an area of knowledge that focuses on the study of the genetic structure of populations. In contrast, other biological fields, such as Embryology, were excluded from the MS (Fox Keller 2000, Amundson 2005, Love 2006). Evolutionary processes were thus defined as those that generate changes in populations' gene frequencies (Ridley 2004) ${ }^{1}$. Besides, different mechanisms were proposed to explain those changes: natural selection (as the main evolutionary mechanism), migration, mutation and genetic drift. This theoretical blooming was reinforced by the development of a new experimental methodology for the study of evolutionary processes: changes in gene frequencies could be replicated in experimental populations, thus allowing the imitation of microevolutionary processes in laboratories. In addition, mathematical equations of Population Genetics were implemented as key tools for the analysis of microevolutionary changes.

As directional natural selection was one of the main evolutionary mechanisms considered by the MS, we will focus our analysis on the temporal characteristics of this kind of microevolutionary process. In the first place, we will briefly describe what these selective processes consist of. Let us consider a simple scenario: the evolution of a gene that has two allelic variants with different frequencies in the population (for example, 0.1

\footnotetext{
${ }^{1}$ It is noteworthy that the MS contained various divergent positions regarding this conception of evolutionary processes. While the referred notion was rejected by some architects of the MS such as Ernst Mayr, it has also been defended by others such as Theodosius Dobzhansky (Amundson 2005). Despite this disagreements, the aforementioned conceptualization of evolutionary change has been at the core of Population Genetics and is still the principal definition used by evolutionary biologists (Ridley 2004).
}

Manuscrito - Rev. Int. Fil. Campinas, v. 39, n. 3, pp. 121 - 147, jul.-set. 2016. 
and 0.9 respectively) and directional selection favouring the variant of lower initial frequency (0.1). Population Genetics' models postulate that gene frequencies will change over time in a way that increases the mean fitness value of the population up to a local maximum. In our example, these models predict the increase of the lower initial frequency variant. Thus, direction in these microevolutionary processes is given by the maximization or optimization of the population's mean fitness value ${ }^{2}$. The evolution of the gene frequencies can also be graphically depicted through 'adaptive topographies' (Ridley 2004). These surfaces contain an 'adaptive peak' which represents the maximum mean fitness value of the topography. According to the maximization principle, it is expected that populations will reach the adaptive peak due to the action of natural selection ${ }^{3}$. Let us now analyse the temporal characteristics of these processes.

As a consequence of the principle of maximization of population's mean fitness, the trajectory of these processes can be conceived of as linear. In relation to the second category, the type of process being analyzed usually admits the possibility of reversions to previous allelic frequencies' states in the populations. A classic example of reversibility (though controversial, see Ridley 2004), has been recognized in natural populations of the peppered moth (Biston betularia). The population frequencies of the light and melanic morphs of the peppered moth varied significantly during the twentieth century in response to changes in the levels of environmental pollution: which morph predominated at a specific time depended on the magnitude of environmental pollution. Thus, selective microevolutionary processes present this kind of flexibility that implies the possibility of reverting to previous gene frequencies' states as a consequence of changes in selective pressures.

2 This principle is not only applied in directional selection models but also in other models of evolution through natural selection.

${ }^{3}$ Even though there are alternative proposals that characterise microevolutionary processes' directionality differently (such as Sewall Wright's Shifting Balance model), the model described here has been the most accepted and applied by population geneticists (Ridley 2004).

Manuscrito - Rev. Int. Fil. Campinas, v. 39, n. 3, pp. 121 - 147, jul.-set. 2016. 
Furthermore, we found that most Population Genetics' models assume that the rate of change of microevolutionary processes is uniform. This uniformity results from the fact that the parameters on which the gene frequencies' rate of change depends on (mainly the selection coefficient) are considered as constants (fixed values) ${ }^{4}$. Qualitatively expressed, most authors of the MS defended the principle of evolutionary adaptive gradualism (disagreeing with other approaches that will be presented in Section 3.2). From this point of view, populations are fairly adapted to their environment and any abrupt change on gene frequencies would inevitably move them away from an adaptive peak. Therefore, only small changes would allow populations to slowly and gradually approach the corresponding adaptive peak and survive.

Finally, microevolutionary processes would occur in a relatively short span of time, considered in evolutionary terms (i.e., in a few generations). This duration allows these processes to be studied using experimental populations and considering only a few generations. Moreover, macroevolutionary changes were assumed to occur due to the accumulation of small changes over longer periods of time (a statement defended by some of the principal authors of the MS such as Ernst Mayr 1942 and G.G. Simpson 1953). Controversies relating to this last principle constituted one of the main criticisms that the MS has suffered, as we will develop in the next section.

\subsection{Macroevolutionary processes: life's history discontinuities and irreversibilities}

As we have already advanced, in the 1970s some of the main principles of the MS were severely challenged, including the explanation of macroevolutionary phenomena through microevolutionary mechanisms. Critics of the MS outlined the need to recognize specific mechanisms that generate macroevolutionary processes such as the origin of new species and the changes in major taxa (Gould and Eldredge 1977, Gould and Lewontin

4 Even though it is possible that these parameters' values change from one generation to the next, this possibility is not usually considered in the general models of Population Genetics.

Manuscrito - Rev. Int. Fil. Campinas, v. 39, n. 3, pp. 121-147, jul.-set. 2016. 
1979). With that purpose they emphasized the relevance of morphometric analysis of fossils and extant species, thus defending the importance of Paleontology and Morphology in the study of evolution (Eldredge and Gould 1972, Gould and Eldredge 1977, Alberch et al. 1979, Wake et al. 1983, Seilacher 1984). Also, new theoretical models regarding macroevolutionary processes and new hypotheses concerning the nature of those changes were postulated. One of the main proposals, the Theory of Punctuated Equilibria (Eldredge and Gould 1972), refers precisely to the temporal characteristics of macroevolutionary processes. We will focus on this theoretical framework for the analysis of the temporality of macroevolutionary processes.

The most remarkable difference between the Theory of Punctuated Equilibria and the MS's characterization of evolutionary temporality corresponds to the variability in the rate of change of macroevolutionary processes. Briefly, the Theory of Punctuated Equilibria postulates that species do not undergo major changes throughout most of their evolutionary history. In this so-called periods of stasis, species would only experience minor alterations. In contrast, macroevolutionary changes would occur in relatively short periods of time (thousands of years). This renewed interpretation of the fossil record would indicate that macroevolutionary processes do not occur uniformly over time, and that their timescales would not be compatible with laboratory imitations.

Moreover, regarding the other categories of our temporal taxonomy, we found that several characteristics of macroevolutionary processes are related to their consideration as historical events ${ }^{5}$. Therefore, the study of evolutionary history requires a form of historical narrative. As Gould stated: "[The history is] an irreversible sequence of unrepeatable events. Each moment occupies its own distinct position in a temporal series, and all

5 From this perspective, history is considered as a sequence of unrepeatable phenomena due to "the statistical improbability that the incalculable number of independent configurations antecedent to and comprising any historical event should ever occur twice" (Gould 1970, p. 208). The historical and irreversible nature of macro-evolutionary processes has been widely discussed by Gould (1970, 1987, 2002), among other authors.

Manuscrito - Rev. Int. Fil. Campinas, v. 39, n. 3, pp. 121 - 147, jul.-set. 2016. 
moments considered in proper sequence, tell a story of linked events moving in a direction" (1987, p. 11). From this approach, it is also believed that chance and contingency play a key role in the generation of unique events in the history of life (Gould 1987, 2002). Thus, according to its historical nature, macroevolutionary processes would present a linear type of trajectory and would be irreversible.

Finally, the duration of macroevolutionary processes would be larger than the extension of microevolutionary processes. It should be noted that, although macroevolutionary changes (e.g. speciation) occur in short intervals of time compared to the length of stasis periods, they are typically longer than the microevolutionary processes considered in the MS. The longer duration of macroevolutionary processes (combined with their historical nature) has possibly prevented their replication in the laboratory. In the next section we will proceed to analyze the temporality of developmental processes.

\subsection{Developmental processes: the recursive construction of organisms}

Traditionally, ontogenetic processes were the subject of study of Embriology. However, around the 1960s, this field suffered major changes, mainly due to the incorporation of molecular methods and the consolidation of an increasingly genetic approach (Fox Keller 2000). Embryology thus acquired the name of Developmental Biology. This area specifically studies the processes of morphogenesis (formation of organs and tissues) and other changes experienced by organisms during their lifetime. Such processes involve growth and differentiation of structures throughout the life cycle, also with changes in physiology and gene expression. Hence, multiple biological levels (molecular, cellular, tissular, organismic) are included in the study of development (Gilbert 2006).

Regarding the above, two types of approaches might be distinguished in current Developmental Biology. One of the approaches focuses on structural changes in organs and tissues, thus continuing with the old anatomical tradition of Embryology (e.g. Kempermann et al. 1997, Denver 1998, Krain and Denver 2004). The other perspective focuses on the molecular changes involved in tissues and organs differentiation (illustrated by works such as Cohn and Tickle 1999, Zúñiga et al. 1999, Basch et al.

Manuscrito - Rev. Int. Fil. Campinas, v. 39, n. 3, pp. 121-147, jul.-set. 2016. 
2006). Since these two approaches present different temporal characteristics we will analyze them separately below.

\subsubsection{Developmental processes' temporality from the anatomical approach}

The anatomical tradition of Developmental Biology has mainly focused on the description of the modifications of structures, tissues and organs at different stages of species' development. Anuran's (primarily frogs) and chickens' 'life cycles' have been relevant objects of study of developmental processes until today. We will describe these processes while exploring their temporal characteristics below 6 .

We will begin analyzing the type of trajectory of these developmental processes. In principle, the key concept of 'life cycle' refers to the repetition of the same pattern of stages in the development of organisms of a given species, generation after generation. However, when the way life cycles are effectively addressed is further analyzed, it is noticeable that what is actually being studied is only some aspect of the formation of structures during some stage/s of the organism's development, ruling out the analysis of subsequent generations. Thus, this approach generally focuses on one single generation, excluding the cyclical aspect of developmental processes (e.g. Denver 1998, Krain and Denver 2004). Consequently, development is studied as a linear and irreversible sequence of events, involving a progressive increase in complexity (Gilbert 2006). Usually, this increase in complexity is related to an increment in structural and functional heterogeneity, and also to the emergence of entities and properties of new levels of organization. These features contribute to explaining the irreversibility of developmental processes. However, it should be mentioned that, under certain circumstances, there are some exceptional cases in which reversion of certain developmental processes is possible. For instance, experiments of de-differentiation of cell nuclei (e.g., cloning experiments)

\footnotetext{
${ }^{6}$ It should be mentioned that genetic and molecular tools have nowadays been included in the investigation of development from an anatomical perspective, although this research program still centres its attention in structural and physiological changes during development (e.g. Kempermann et al. 1997, Denver 1998, Krain and Denver 2004).
}

Manuscrito - Rev. Int. Fil. Campinas, v. 39, n. 3, pp. 121 - 147, jul.-set. 2016. 
and regeneration of certain tissues involve reversions of cellular, physiological and morphological developmental processes.

On the other hand, we found that the developmental rate of change is generally assumed to be variable. An extreme case of such variability is found in spores (resistant structures) of some fungi and bacteria, in which development ceases temporarily until an environmental stimulus reactivates the process.

Finally, regarding duration, this approach has focused on some stage/s of development or, at most, on processes that occur in the course of a single generation. In any case, as we have mentioned above, the study of anatomical processes does not exceed the lifetime of one generation. Let us now analyse the temporality of the molecular processes of development.

\subsubsection{The molecular processes of developmental and its temporality}

In relation to the approach that specifically studies the molecular changes involved in development (e.g. Cohn and Tickle 1999, Basch et al. 2006), we found that most works focus on the molecular signals which act as inducers of differentiation of cells and tissues during morphogenesis. Thus, the study of the development of many structures (e.g. vertebrates limbs, neural tube, among others) includes the description of the signals that are mutually exchanged between different cell groups during differentiation. In these phenomena, called 'reciprocal induction', when a particular cell group receives a signal, it sends out a new signal to the emitting cell group to continue the differentiation process. Thus, these molecular signals are responsible for the continuation of cellular differentiation and tissue formation. These 'cell dialogues' are consecutively repeated throughout the entire process of differentiation. An example in which the dynamics of these dialogues has been extensively revealed is the development of tetrapod limbs (Zúñiga et al. 1999).

Starting with the analysis of the temporal characteristics, the type of trajectory of these processes can be depicted as helical, due to the recursion involved in the cell dialogues that we have described. In this case, the initiation of each state of the process is the consequence of a product (a molecular signal) of the previous state.

Manuscrito - Rev. Int. Fil. Campinas, v. 39, n. 3, pp. 121-147, jul.-set. 2016. 
Regarding the remaining temporal categories, we found that although this approach emphasizes the continuity of developmental processes (as reciprocal inductions generate their continuous advance), it is not generally specified whether the rate of change is uniform or variable. In addition, as we have previously mentioned, the increase in the degree of differentiation and specialization generally involves the irreversibility of these processes (with the named exceptions in which certain genetic and molecular processes could be reversed). Finally, the duration of these processes is usually shorter than the corresponding anatomical ones studied in the previous approach.

To sum up, Developmental Biology has studied ontogenetic processes conceiving them as sequences of states that are repeated in each generation. Thus, changes that fall beyond this period of time are not addressed in this field of study. In contrast, the relationships and interactions between developmental and transgenerational (evolutionary) processes will be studied in the area that we will analyze in Section 4: EvoDevo.

\subsection{Summary of results of evolutionary and developmental processes' temporality}

In Table 1 we summarize the temporal characteristics found in evolutionary and developmental processes.

\begin{tabular}{|c|c|c|c|c|}
\hline \multirow[b]{3}{*}{$\begin{array}{l}\text { Temporal } \\
\text { categories }\end{array}$} & \multicolumn{4}{|c|}{ Kind of process } \\
\hline & \multicolumn{2}{|c|}{ Evolutionary processes } & \multicolumn{2}{|c|}{$\begin{array}{c}\text { Developmental } \\
\text { processes }\end{array}$} \\
\hline & Microevolution & Macroevolution & Anatomical & Molecular \\
\hline $\begin{array}{l}\text { Type of } \\
\text { trajectory }\end{array}$ & Linear & Linear & Linear & Helical \\
\hline $\begin{array}{l}\text { Rate of } \\
\text { change }\end{array}$ & Uniform & Variable* & Variable & $\begin{array}{l}\text { Uniform or } \\
\text { variable }\end{array}$ \\
\hline Reversibility & Yes* & No & $\begin{array}{c}\text { No (with } \\
\text { exceptions) }\end{array}$ & $\begin{array}{c}\text { No (with } \\
\text { exceptions) }\end{array}$ \\
\hline Duration & $\begin{array}{l}\text { Long (some } \\
\text { generations) }\end{array}$ & $\begin{array}{l}\text { Very long (thousands } \\
\text { of generations) } *\end{array}$ & $\begin{array}{l}\text { Short (one } \\
\text { generation, a } \\
\text { lifetime) }\end{array}$ & Short \\
\hline
\end{tabular}

Table 1. Summary of the temporal characteristics of microevolutionary, macroevolutionary and developmental processes. The main differences found between the three approaches are marked $(*)$.

Manuscrito - Rev. Int. Fil. Campinas, v. 39, n. 3, pp. 121 - 147, jul.-set. 2016. 
These results show that, not only different kinds of biological processes present distinct temporal characteristics, but also that the same kind of biological process might exhibit diverse temporalities. This happen to be the case with evolutionary processes, as micro and macroevolution present differing temporal characteristics, which was an expected result. However, we also found that developmental processes might show several temporalities, since anatomical and molecular approaches differ on some properties (mainly on the type of trajectory). In addition, it should be noted that, although some characteristics of different kinds of processes have been identified as coincident in Table 1, they might also diverge, as we have pointed out throughout Section 3 (for example, microevolutionary processes show a linear type of trajectory due to the increase of population's mean fitness, while macroevolutionary processes' linearity is related to their historical nature). Overall, the results found in this section already show a remarkable diversity in biological processes' temporality. Let us now analyze the temporal characteristics of EvoDevo's processes.

\section{EvoDevo: the integration of evolutionary and developmental processes}

As we advanced in Section 1, the field of EvoDevo currently comprises diverse research programs with methodological and theoretical differences (Laubichler and Maienschein 2007, Müller 2008, Pigliucci and Müller 2010). We will now analyze the temporality of the processes addressed by three of the major EvoDevo's research programs as distinguished by Müller (2008): Evolutionary Developmental Genetics (Section 4.1), Comparative Embriology and Morphology (Section 4.2), and Ecological Evolutionary Developmental Biology (EcoEvoDevo) (Section 4.3). We will finish Section 4 with a summary of the obtained results for each of EvoDevo's research programs (Section 4.4).

\subsection{Evolutionary Developmental Genetics}

Manuscrito - Rev. Int. Fil. Campinas, v. 39, n. 3, pp. 121-147, jul.-set. 2016. 
At present, Evolutionary Developmental Genetics is EvoDevo's most conspicuous program (Müller 2008). This approach investigates the genetic regulatory networks that control development and are associated with the evolution of organic form (Müller 2008). Specifically, this research program has focused on the study of the molecular-genetic changes (i.e., changes in gene's sequences and the regulatory function of their products) associated with macroevolutionary transformations (Cohn and Tickle 1999, Ronshaugen et al. 2002, Lee et al. 2003, Pick and Heffer 2012). The processes involved in these changes are addressed by comparing the expression and function of the regulatory developmental genes of different species. Such comparisons lead to conclusions about the genetic changes involved in the evolution of certain phenotypic differences between species or higher order taxonomic groups.

Hox genes constitute a paradigmatic subject of study of this research program. We will explore the temporal characteristics of the processes addressed in Evolutionary Developmental Genetics by considering a wellstudied example: the changes in $U b x$ and $A b d A$, two Hox genes which are associated with the development of legs in crustaceans and insects (Ronshaugen et al. 2002 constitutes a classic work on this topic). These taxa are believed to share a common ancestor with legs in the whole trunk. Making use of the distinctive experimental methodology of this research program, it was established that $U b x$ and $A b d A$ sequences would have experienced particular changes in the evolutionary branch that gave rise to insects from that common ancestor. These changes would have affected genes' function: while they suppress leg formation in insects' abdomen, they still contribute to leg development in crustaceans (which maintain the common ancestor's body plan). Thus, changes in developmental regulatory genes contribute to explaining morphological macroevolutionary changes in higher taxa.

We will begin our temporal analysis by considering the type of trajectory of these processes. As the purpose of this research program is to reconstruct the sequence of genetic changes in lineages' history, this perspective recovers the linearity associated with the historical nature of macroevolutionary processes. However, it should be mentioned that we also found here some temporal characteristics of the developmental processes described in Section 3.3. For example, the study of the molecular-genetic

Manuscrito - Rev. Int. Fil. Campinas, v. 39, n. 3, pp. 121 - 147, jul.-set. 2016. 
changes in developmental regulatory networks includes recursion, a distinctive property of the reciprocal inductions involved in such networks. Even though the inclusion of different kinds of trajectories is an interesting feature (since it shows that EvoDevo does actually present the temporal characteristics of the different kinds of processes it aims to integrate), it is also remarkable that new temporal characteristics for evolutionary processes arise in this approach. We will then specifically focus our analysis on the temporalities involved in the evolutionary dimension of the processes studied by EvoDevo.

Firstly, we found that the reversion of macroevolutionary changes is considered somehow possible from this approach. This notion lies at the heart of this research program's methodology, since the genetic experimental approach assumes that macroevolutionary changes can be at least partially imitated by experimentally introducing certain mutations in regulatory genes and studying their effects (this methodology can be seen in detail, for example, in the experiments performed by Ronshaugen et al. 2002).

Moreover, we found that this approach assumes the rate of change to be variable. Notably, this is one of the most distinctive properties of macroevolutionary processes, as we described in Section 3.2. Thus, the direct association between macroevolutionary and genetic changes assumed by the Evolutionary Developmental Genetics program is remarkably compatible with the pronounced variability of the rate of change characteristic of macroevolution.

Finally, regarding the duration of these processes, the Evolutionary Developmental Genetics approach implements experimental designs that are thought to imitate macroevolutionary changes in a much shorter time, as we already mentioned. In this sense, authors like Gould saw at the onset of this research program the promising possibility of addressing macroevolutionary historical events through a novel experimental methodology, different from the paleontological and morphological approaches (Gould 1977, 2002). Let us now continue with the analysis of another EvoDevo's major research programs: the Comparative Embriology and Morphology.

Manuscrito - Rev. Int. Fil. Campinas, v. 39, n. 3, pp. 121-147, jul.-set. 2016. 


\subsection{The Comparative Embriology and Morphology Program}

The Comparative Embriology and Morphology Program addresses various macroevolutionary processes related to developmental changes such as evolutionary innovations, heterochronies and constraints, among others. Thus, unlike the Evolutionary Developmental Genetics Program, this approach focuses on the examination of morphological changes between species, including the study of developmental processes at the cellular and tissular levels. It also incorporates the analysis of fossils, along with molecular tools, among other methodologies (Mabee 2000, Wu et al. 2006, Tokita et al. 2007, Müller 2008).

We will analyse the temporal characteristics of this approach by focusing on one of its main themes: constraints. Although the definition of constraints is still debated (see, for example, Beldade and Brakefield 2003), developmental and phyletic constraints are usually distinguished. Developmental constraints are generally defined as internal factors of developmental systems that bias the production of phenotypic variants, or that limit species' phenotypic variability (Maynard Smith et al. 1985). On the other hand, phyletic constraints are given by the species own evolutionary history, and canalise the potential changes of the lineage. Noteworthy, most authors do not consider constraints as mere limitations. Instead, they are thought to productively contribute to developmental and evolutionary processes (Arthur 2001, Gould 2002).

A classic case of study of constraints involves the number of body segments of different species of centipedes. The number of body segments varies greatly in this class of organisms, although presenting always an odd number. By studying centipedes' development, a particular mechanism that could explain this pattern of phenotypic variation was found. This mechanism is based on the expression of segmentation genes in two stages during development. The first stage involves the expression of segmentation genes that determine the separation of double segments. The second stage includes another cycle of expression of segmentation genes in bands that lie between the double segments. Subsequently, one of the so formed segments joins the cephalic area. Thus, the described mechanism explains the constant body segments' odd number found in all centipede species (the detailed mechanism can be found in Chipman et al. 2004).

Manuscrito - Rev. Int. Fil. Campinas, v. 39, n. 3, pp. 121 - 147, jul.-set. 2016. 
Regarding the temporal characteristics of these processes, it is possible to identify the properties described for developmental processes in Section 3.3. Among those properties, irreversibility stands out, as the developmental mechanisms involved in constraints generate strong regularities and canalise development through certain paths, while preventing others. It is precisely this developmental irreversibility which helps to explain the irreversibility of the related macroevolutionary phenomena: the evolutionary persistence of a distinctive body plan in a whole class of organisms, through a very long span of time.

As for the other evolutionary temporal characteristics of these processes, they could not be further identified, mainly because groups' evolutionary histories are not deeply studied by the Comparative Embriology and Morphology approach. Besides, our taxonomy seems to be more suitable for analyzing changes in biological systems rather than persistence without alterations, such as in this case of constraints. Despite these limitations, it seems possible to assume some of the characteristics of macroevolutionary processes described in Section 3.2, such as their long duration. In the next section we will examine a third research program of EvoDevo: the Ecological Evolutionary Developmental Biology (EcoEvoDevo).

\subsection{Ecological Evolutionary Developmental Biology (EcoEvoDevo)}

EcoEvoDevo aims to integrate the study of evolution and development taking also into account the relationships of organisms with their environment (Gilbert and Epel 2009, Abouheif et al. 2014). One of the main subjects of study of this field corresponds to environmental induction processes, i.e., the generation of evolutionary relevant phenotypic variants due to the direct influence of particular environmental factors on organisms' development. Different kinds of processes involving environmental induction and developmental plasticity have been described (mainly genetic assimilation, and genetic and phenotypic accommodation) (West-Eberhard 2003, Gilbert and Epel 2009). Since we cannot describe in detail all these processes here, we will focus on West-Eberhard's proposal in order to highlight some of the novel temporal characteristics that emerge from this perspective (West-Eberhard 2003 and 2005, Gilbert and Epel 2009). This author postulated an explanatory model for the emergence of

Manuscrito - Rev. Int. Fil. Campinas, v. 39, n. 3, pp. 121-147, jul.-set. 2016. 
new phenotypes which combines the aforementioned processes. According to this model, new phenotypic characteristics could arise due to genetic mutations or through environmental induction. Once this happens, phenotypic accommodation, i.e. the mutual adaptive tuning between different aspects of a phenotype after a developmental change, could follow. These processes would allow for the generation of viable phenotypes in response to a prior modification in development. Consequently, at the population level, novel selectable phenotypes would arise, and a typical microevolutionary selective process might start. In addition, if the new phenotype is adaptive and has a genetic component, genetic accommodation (or assimilation) (i.e., genetic change in the population) may take place. As a result, the new phenotype might then appear in the population even in the absence of the environmental inducer input. Eventually, this kind of novelties may originate evolutionary innovations, that is, macroevolutionary changes.

So, how can the temporal characteristics of these processes be characterized? Let us begin with their duration. First, it should be said that environmental induction can act on several organisms at the same time and that this inducing environment is usually also the selective environment. In this case, new phenotypes are likely to be tested quicker and their population frequencies are expected to change faster than what is assumed in the models of the MS (Shimada et al. 2010). Thus, environmental induction, together with the other phenomena incorporated in West-Eberhard's model, could accelerate the appearance and propagation of new phenotypes and possibly, of macroevolutionary processes as well. A second novelty in these processes corresponds to the appearance of a new kind of reversibility originated by environmental induction. If the inducer environmental factor ceases its action before genetic stabilization occurs, the induced phenotypes would disappear from the population, thus causing a regression to a population's previous state. Third, environmental induction also makes possible a new type of trajectory: a cyclical one. For example, when a population inhabits a seasonally changing environment, the capacity to express diverse phenotypic variants due to seasonal inducers is usually selected (phenomenon called genetic accommodation). Several cases of this phenomenon are known. As an illustration, the moth Manduca sexta (tobacco hornworm) presents a black larva in winters (colour that helps to increase

Manuscrito - Rev. Int. Fil. Campinas, v. 39, n. 3, pp. 121-147, jul.-set. 2016. 
the absorption of solar energy) and a green-turquoise larva in summers (which provides greater camouflage and defense against predation) (Suzuki and Nijhout 2006). Finally, regarding the rate of change, as these processes can be studied using the models of Population Genetics (such as the selective models that we have described in Section 3.1) they usually present a uniform rate of change. However, as we have mentioned, these processes can also originate macroevolutionary changes, i.e., evolutionary discontinuities in a group of organisms. So, in brief, EcoEvoDevo presents a remarkable novel combination of temporal characteristics which emerge from the integration of developmental, micro and macroevolutionary processes. In the next section we will summarize the results of the temporal analysis of EvoDevo's research programs.

\subsection{Summary of results of EvoDevo processes' temporality}

In Table 2 we summarize the temporal characteristics of the processes addressed by EvoDevo's three major research programs.

\begin{tabular}{|c|c|c|c|}
\hline $\begin{array}{c}\text { Field of study/ } \\
\text { Temporal } \\
\text { characteristics }\end{array}$ & $\begin{array}{c}\text { Evolutionary } \\
\text { Developmental } \\
\text { Genetics }\end{array}$ & $\begin{array}{c}\text { Comparative } \\
\text { Embriology and } \\
\text { Morphology }\end{array}$ & EcoEvoDevo \\
\hline $\begin{array}{c}\text { Type of } \\
\text { trajectory }\end{array}$ & Linear & Linear & Cyclic \\
\hline Rate of change & Variable & Variable & Uniform/variable \\
\hline Reversibility & Yes & No & $\begin{array}{c}\text { Yes (from } \\
\text { environmental } \\
\text { induction) }\end{array}$ \\
\hline Duration & Very long & Very long & $\begin{array}{c}\text { Long (even for } \\
\text { macroevolutionary } \\
\text { changes) }\end{array}$ \\
\hline
\end{tabular}

Table 2. Summary of the temporal characteristics found in three of the major research programs of EvoDevo (considering their evolutionary dimension only).

As shown in Table 2, EvoDevo shows a variety of temporalities in its diverse research programs. Besides, these approaches introduce new

Manuscrito - Rev. Int. Fil. Campinas, v. 39, n. 3, pp. 121-147, jul.-set. 2016. 
temporal characteristics with respect to those present in the fields of Evolutionary and Developmental Biology. In this sense, EcoEvoDevo research program seems to introduce the most remarkable novelties: a new (cyclical) type of trajectory; a novel kind of reversibility related to environmental induction; and even a new possible duration for macroevolutionary phenomena, which might be shortened due to the introduction of novel mechanisms (such as environmental induction and phenotypic accommodation). Thus the integrative perspective on the study of developmental and evolutionary processes proposed by EvoDevo allowed for novel kinds of temporal characteristics and for the recognition of a diversity of temporalities by different research programs. In the next section we offer some general conclusions about the multitemporality of biological processes and examine some implications of these results regarding the relevance of the biological perspectives on the issue of temporality.

\section{Conclusions}

After analyzing the temporal characteristics of developmental and evolutionary processes we can ratify our main hypothesis: EvoDevo, as a field that integrates different kinds of biological processes, presents multiple temporalities. Besides, EvoDevo not only introduces new temporal characteristics (summarized in Section 4.4) when integrating processes that used to be studied separately, but also comprises different research programs which recognize a variety of temporalities for the processes they address.

Overall, the results summarized in Sections 3.4 and 4.4 not only show a remarkable diversity of temporalities in different biological fields of study, but also within each of them. Thus, biological processes' temporality seems to be extremely diverse and flexible. Such diversity has been increasingly recognized throughout the twentieth century, as new perspectives and biological fields of study emerged and diversified. In this sense, when developmental and evolutionary processes are addressed separately (i.e., by Developmental Biology and Evolutionary Biology respectively), such temporal heterogeneity is only partially noticed. Conversely, EvoDevo,

Manuscrito - Rev. Int. Fil. Campinas, v. 39, n. 3, pp. 121 - 147, jul.-set. 2016. 
conceived as an interdisciplinary area which focuses on the interactions between different kinds of biological processes, seems to fully show the flexibility and diversity of life-processes' temporality. This observation contributes to showing the importance of implementing an integrative perspective for grasping living processes' diversity and complexity in a more fully way.

Finally these results allow us to offer some conclusions regarding the relevance of Philosophy of Biology's insights on temporality. The remarkable diversity of biological temporalities that we have found in this paper seems to be related to the multiplicity of levels of organization and complexity which are distinctive features of biological processes (Rendón 2013). Thus, even when Physics has provided useful insights about the microscopic components and physical characteristics of natural entities and processes, the unique nature of living processes could not be fully apprehended through the perspectives offered by that discipline. In a similar vein, when the diversity of temporalities found in this paper (even taking into account a small number of biological processes) is considered, Physics' perspectives on time and temporality do not seem to be enough to wholly understand the complex multitemporality of living beings' processes. This conclusion supports the pertinence of biological insights and the relevance that the contributions from Philosophy of Biology could have on the complex, extensive and multifaceted issues of time and temporality.

\section{Bibliography}

Abouheif, E., Favé, M. J., Ibarrarán-Viniegra, A. S., Lesoway, M. P., RAFiqI, A. M., RAJakUmar, R. "Eco-Evo-Devo: The time has come”. Adv. Exp. Med. Biol, 781, pp. 107-125, 2014.

Alberch, P., Gould, S. J. , Oster, G. F., Wake, D. B. "Size and shape in ontogeny and phylogeny”. Paleobiology, 5(3), pp. 296-317, 1979.

Amundson, R. The Changing Role of the Embryo in Evolutionary Thought Roots of Evo-Devo. Cambridge: Cambridge University Press, 2005.

Manuscrito - Rev. Int. Fil. Campinas, v. 39, n. 3, pp. 121-147, jul.-set. 2016. 
ARTHUR, W. "Developmental drive: an important determinant of the direction of phenotypic evolution". Evolution \& development, 3(4), pp. 271-278, 2001.

BASCH, M. L., Bronner-Fraser, M., García-CAStro, M. I. „Specification of the neural crest occurs during gastrulation and requires Pax7". Nature, 441(7090), pp. 218-222, 2006.

Beldade, P., BRAKefield, P. M. "The difficulty of agreeing about constraints". Evolution \& development, 5(2), pp. 119-120, 2003.

Chipman, A. D., ArThur, W., AKam, M. "A double segment periodicity underlies segment generation in centipede development". Current Biology, 14(14), pp. 1250-1255, 2004.

CoHn, M. J., TiCkLE, C. "Developmental basis of limblessness and axial patterning in snakes". Nature, 399(6735), pp. 474-479, 1999.

Cracraft, J. "Phylogeny and evo-devo: Characters, homology, and the historical analysis of the evolution of development". Zoology, 108, pp. 345-356, 2005.

DENVER, R. J. "Hormonal Correlates of Environmentally Induced Metamorphosis in the Western Spadefoot Toad, Scaphiopus hammondi". General and comparative endocrinology, 110(3), pp. 326-336, 1998.

DowDen, B. “Time”. The Internet Encyclopedia of Philosophy, ISSN 2161-0002, http://www.iep.utm.edu/, 2016.

ElDredGE, N., Gould, S. J. "Punctuated equilibria: an alternative to phyletic gradualism”. In T.J.M. Schopf (ed.) (1972), pp. 82-115.

Fox Keller, E. Lenguaje y Vida. Buenos Aires: Ediciones Manantial, 2000.

GILBERT S.F., EPEL, D. Ecological Developmental Biology: Integrating Epigenetics, Medicine, and Evolution. Sunderland, MA: Sinauer Associates Inc. Publishers, 2009.

Gould, S. J. "Dollo on Dollo's law: irreversibility and the status of evolutionary laws". Journal of the History of Biology, 3(2), pp.189-212, 1970.

Manuscrito - Rev. Int. Fil. Campinas, v. 39, n. 3, pp. 121 - 147, jul.-set. 2016. 
Ontogeny and Phylogeny. Cambridge, Massachusetts: The Belknap Press of Harvard University press, 1977.

Time's Arrow, Time's Cycle: Myth and Metaphor in the Discovery of Geological Time. Cambridge, Mass: Harvard University Press. 1987.

The Structure of the Evolutionary Theory. Cambridge, Massachusetts: The Belknap Press of Harvard University Press, 2002.

, EldReDge, N. "Punctuated equilibria: The Tempo and Mode of Evolution reconsidered”. Paleobiology, 3, pp. 115-151, 1977.

, LeWOntin,R. C. "The spandrels of San Marco and the Panglossian paradigm: a critique of the adaptationist programme". Proceedings of the Royal Society of London. Series B. Biological Sciences, 205(1161), pp. 581-598, 1979.

Haldane, J.B.S. El tiempo en la biología. Mexico: Universidad Nacional Autónoma de México, 1967.

Kempermann, G., KuHn, H. G., Gage, F. H. "More hippocampal neurons in adult mice living in an enriched environment". Nature, 386(6624), pp. 493-495, 1997.

Krain, L. P., DenVer, R. J. "Developmental expression and hormonal regulation of glucocorticoid and thyroid hormone receptors during metamorphosis in Xenopus laevis". Journal of Endocrinology, 181(1), pp. 91-104, 2004.

LAUBiCHLER M. D., MAIENSCHEIN, J. From Embryology to Evo-devo: a history of developmental evolution. Cambridge, Massachusetts: The MIT Press, 2007.

Lee, P. N., Callaerts, P., De Couet H. G., Martindale, M. Q. "Cephalopod Hox genes and the origin of morphological novelties”. Nature, 424(6952), pp. 1061-1065, 2003.

LOvE, A. C. "Evolutionary morphology and Evo-devo: Hierarchy and novelty". Theory in biosciences, 124, pp. 317-333, 2006.

Manuscrito - Rev. Int. Fil. Campinas, v. 39, n. 3, pp. 121-147, jul.-set. 2016. 
MABEE, P. M. 2000. "Developmental data and phylogenetic systematics: evolution of the vertebrate limb". American Zoologist, 40(5), pp. 789$800,2000$.

Maynard Smith, J., Burian, R., Kauffman, S., Alberch, P., Campbell, J., GOODWIN, B., (...) Y WOLPERT, L. "Developmental constraints and evolution: a perspective from the Mountain Lake conference on development and evolution". Quarterly Review of Biology, 60 (3), pp. 265-287, 1985.

MAYR, E. Systematics and the Origin of Species. Nueva York: Columbia University, 1942.

Mineldi, A., FusCo, G. Evolving Pathways: key themes in evolutionary developmental biology. Cambridge: Cambridge University Press, 2008.

MORIN, E. El Método. vol. II: La vida de la vida. Madrid: Cátedra, 1983.

Müller, G. B. "Evo-devo as a discipline”. In A. Minelli y G. Fusco (eds.) (2008), pp. 5-30.

PICK L., HEFFER, A. "Hox gene evolution: multiple mechanisms contributing to evolutionary novelties". Ann N Y Acad Sci, 1256, pp. 15-32, 2012.

Pigliucci, M., MÜller, G. Evolution - the extended synthesis. Cambridge, Massachusetts: The MIT Press, 2010.

Rasskin-Gutman, D, Esteve-Altava, B. "Modeling Evo-Devo: Broken Hierarchies and Multiple Scales of Organization and Complexity". AIP Conference Proceedings, 1167, pp. 43-55, 2009.

REISS, J. O. "The meaning of developmental time: a metric for Comparative Embryology". American Naturalist, 134(2), pp. 170-189, 1989.

RENDÓN, C. A. "Evo-devo como abordaje complejo de la evolución biológica”. Ludus Vitalis, 21(39), pp. 27-42, 2013.

RENDÓN, C.A. "Análisis teórico de las relaciones interdisciplinares en la biología evolutiva del desarrollo (evo-devo)" (Doctoral Thesis). Universidad de Buenos Aires, Buenos Aires, Argentina, 2015.

Manuscrito - Rev. Int. Fil. Campinas, v. 39, n. 3, pp. 121 - 147, jul.-set. 2016. 
RIDLEY, M.R. Evolution (3 ${ }^{\text {rd }}$ edition). Cambridge, MA: Bllackwell Publishing, 2004.

Ronshaugen, M., MCGINNIS, N., MCGINNIS, W. "Hox protein mutation and macroevolution of the insect body plan". Nature, 415(6874), pp. 914-917, 2002.

SAVITT, S. "Being and Becoming in Modern Physics". The Stanford Encyclopedia of Philosophy (Summer 2014 Edition), http://plato.stanford.edu/archives/sum2014/entries/spacetime bebecome/, 2014.

SCHOpF, T.J.M. Models in Paleobiology. SanFrancisco: Freeman, Cooper and Company, 1972.

SEILACHER, A. "Constructional morphology of bivalves: evolutionary pathways in primary versus secondary soft-bottom dwellers”. Palaeontolog, 27(2), pp. 207-237, 1984.

SHIMADA, M., ISHII, Y., SHIBAO, H. "Rapid adaptation: a new dimension for evolutionary perspectives in ecology". Population ecology, 52(1), pp. 514, 2010.

Simpson, G. G. The Major Features of Evolution. New York: Columbia University Press, 1953.

SuZUKI, Y., NijHOUT, H. F. "Evolution of a polyphenism by genetic accommodation”. Science, 311(5761), pp. 650-652, 2006.

TOKITA, M., KIYOSHI, T., ARMSTRONG, K. N. "Evolution of craniofacial novelty in parrots through developmental modularity and heterochrony". Evolution \& development, 9(6), pp. 590-601, 2007.

WAKe, D. B., ROTH, G., WAKE, M. H. "On the problem of stasis in organismal evolution". Journal of Theoretical Biology, 101(2), pp. 211224, 1983.

West-Eberhard, M. J. Developmental plasticity and evolution. New York: Oxford University Press, 2003.

Manuscrito - Rev. Int. Fil. Campinas, v. 39, n. 3, pp. 121-147, jul.-set. 2016. 
WeST-EBERHARD, M. J. "Developmental plasticity and the origin of species differences". Proceedings of the National Academy of Sciences of the United States of America, 102(Suppl 1), pp. 6543-6549, 2005.

Wu, P., Jiang, T.X., Shen, J.Y., Widelitz, R.B., ChuOng, C.M. "Morphoregulation of avian beaks: comparative mapping of growth zone activities and morphological evolution". Developmental Dynamics, 235(5), pp. 1400-1412, 2006.

ZaragüEtA BAgils, R., LeliÈvre, H., TAssy, P. "Temporal paralogy, cladograms, and the quality of the fossil record". Geodiversitas, 26, pp. 381-389, 2004.

ZÚÑigA, A., HARAmis, A. P. G., MCMAhon, A.P., ZelLer, R. "Signal relay by BMP antagonism controls the SHH/FGF4 feedback loop in vertebrate limb buds". Nature, 401(6753), pp. 598-602, 1999.

Manuscrito - Rev. Int. Fil. Campinas, v. 39, n. 3, pp. 121 - 147, jul.-set. 2016. 